\title{
Declaração Universal dos Direitos Humanos, o documento mais importante elaborado pelo homem
}

Maria Luiza Marcílio, diplomada em História pela Universidade de São Paulo - USP, doutorou-se em Paris, na École des Hautes Études en Sciences Sociales, e sua tese sobre a cidade de São Paulo foi o marco da pesquisa em demografia histórica na América Latina. Além de professora titular do Departamento de História, ocupa o importante cargo de presidente da Comissão de Direitos Humanos da Universidade de São Paulo, onde criou a primeira biblioteca virtual em língua portuguesa sobre direitos humanos. É membro do Conselho de Acompanhamento dos Direitos Humanos da Secretaria de Justiça e de Defesa da Cidadania, e integra a Cátedra Unesco para os Direitos Humanos do Instituto de Estudos Avançados da USP. Em 1994, recebeu o prêmio John Simon Guggenheim, concedido a pesquisadores norte-americanos e latino-americanos das Ciências Humanas. Publicou importantes obras sobre o abandono da criança e a questão da educação, tendo seu último livro classificado entre os dez finalistas do 48o Prêmio Jabuti. Nesta entrevista, ela defende a Declaração Universal dos Direitos Humanos como o mais importante documento elaborado pelo homem. Sua experiência permite-lhe afirmar que o Brasil só poderá combater a desigualdade social com uma escola de base de qualidade para todos, além de defender a pesquisa como importante ferramenta para a tomada de decisões, em qualquer área do saber e da sociedade.

Por prof ${ }^{\underline{a}} d r^{\underline{a}}$ Maria Cristina Castilho Costa

e Consuelo Ivo

C \& E: Desde muito jovem você militou nas lutas sociais, enquanto estudava Filosofia no antigo prédio da FFLCH/USP. Como é estar de volta ao mesmo endereço, ocupando a cadeira de presidente da Comissão de Direitos Humanos da USP?

Maria Luiza Marcílio: Uma jovem, como você disse, que sai de um colégio de freiras, onde tudo era proibido, onde não se tinha uma visão boa do mundo, entra na rua Maria Antonia para fazer o curso de História, num momento de efervescência política. Havia intensa mobilização nos partidos e entre os jovens que, na Faculdade de Filosofia, Letras e Ciências Humanas, participavam do 
grêmio da faculdade, de debates e de vários movimentos sociais, como o de Florestan Fernandes, defendendo a escola pública. Tive a sorte de ser convidada e de ingressar na Juventude Universitária Católica - a JUC, ação universitária católica, de onde surgiram pessoas importantes que chegaram a ser Secretários de Estado e Ministros. Foi nesse meio que descobri a vida política e até mesmo o marxismo. Li muito nessa época e acompanhei a intensa militância de esquerda. Nasceu aí minha preocupação com os problemas da solidariedade humana, do direito, da justiça social, como valores que devem vingar em nossa sociedade.

C \& E: Como foi trazer para o País a Demografia?

Maria Luiza: A Demografia não é uma metodologia, mas uma ciência, chamada Demografia Histórica. Essa ciência também estava nascendo na França e o pai era Louis Henry, que foi meu orientador junto com Fernand Braudel. Quando ganhei a bolsa do governo francês, tive a sorte de estar em contato com o próprio Louis Henry, que me orientou de modo a levantar os dados básicos para a minha tese sobre a cidade de São Paulo - eram os registros paroquiais de batismo, os casamentos e óbitos de um período de cem anos. Comecei, rapidamente, a levantar esses dados e levei tudo isso para a França. Em Paris, fui aprendendo as técnicas da Demografia Histórica, com o grupo de pesquisa de Louis Henry que pertencia à Ecòle Pratique, ou Escola Prática de Altos Estudos, transformada, depois, por Braudel, em Escola de Altos Estudos em Ciências Sociais (École des Hautes Études en Sciences Sociales). Em quatro anos defendi a minha tese sobre a cidade de São Paulo e publiquei meu primeiro livro. A tese foi muito bem-aceita pela banca, que a aprovou com mérito e distinção, em 1967, sendo publicada em francês no ano seguinte. Mais tarde, eu mesma a traduzi para publicação pela Edusp.

C \& E: Em 1974?

Maria Luiza: Em 1974. Essa tese, pode-se dizer, foi o registro de batismo da Demografia Histórica na América Latina, pois até então não havia nenhum trabalho nessa área. Quando saí do país, em 1963, eu era professora da PUC, onde havia sido convidada a lecionar. E, mesmo recém-formada, ocupei o cargo de professora titular de História do Brasil, na PUC. Dava aula para os cursos de História, Geografia, Ciências Sociais e Pedagogia. Foi aí que resolvi ir para a França aprender a fazer pesquisa. Escolhi então o maior centro mundial de pesquisa histórica que, na época, contava com uma plêiade de grandes historiadores como Fernand Braudel, Le Roy Ladurie, Jacques Le Goff e Ernest Labrousse.

C \& E: Estudou com bolsa do governo francês?

Maria Luiza: Sim. Quando me formei, abriu-se, pela primeira vez, um concurso para bolsas de um ano na França, para qualquer área do conhecimento. Inscrevime e consegui essa oportunidade. Foi lá que descobri a Demografia Histórica 
e pude obter, na documentação pesquisada, muitos dados sobre nosso país. Na contagem dos registros de batismo, por exemplo, fiquei absolutamente surpresa ao descobrir que $15 \%$ das crianças livres, não os escravos, eram abandonadas ao nascer - chamavam-se expostos. Descobri também que $25 \%$ delas eram ilegítimas. Isto a historiografia nunca tinha abordado. Gilberto Freyre falava da mestiçagem resultante das relações entre o senhor branco e a escrava negra, mas não mostrava claramente essa intensa presença de concubinatos, como eram chamadas as uniões não-formais, e o número alarmante de crianças ilegítimas.

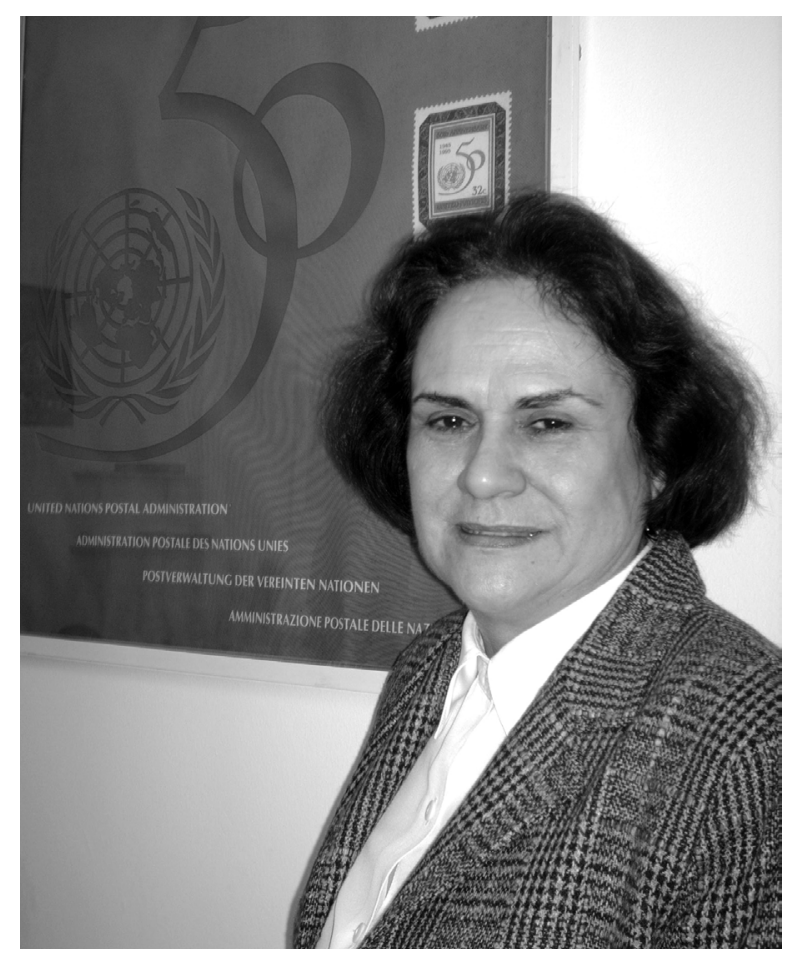

"O Brasil só poderá combater a desigualdade com escola de qualidade para todos."

C \& E: Quer dizer que havia dados que não tinham entrado para a história?

Maria Luiza: Não haviam sido considerados, até porque ninguém descobrira isso. Foi a contagem dos registros de batismos que me forneceu esses dados. Essa descoberta levou-me a pensar: "Mas será que isso só acontece na cidade de São Paulo, nos séculos XVIII, XIX e começo do XX? Ou será uma realidade brasileira? Aconteceu apenas nas cidades, ou também no campo?”. E questionava: "Como a Igreja batizara essas crianças, se era contra o concubinato?". Havia toda uma historiografia mostrando que as visitações do Santo Ofício, e toda legislação, perseguiam casais nessa situação. Comecei a me preocupar com a história da família, o que era uma coisa muito rara, pois havia um patrulhamento ideológico, inclusive na Universidade, que considerava estudos da família como um estudo burguês. Fui muito criticada, na época, pelos estudos de família que encetei, porque as pessoas não estavam entendendo meus objetivos, que eram exibir a realidade social histórica e vigente.

C \& E: Você teve contato com os estudos feministas nesse período em que passou na França?

Maria Luiza: Nunca fui ligada ao feminismo, embora tenha sido sempre cooptada por todos os movimentos feministas para me integrar a eles. E, realmente, colaborei com eles. Assim como lutei para implantar a Demografia Histórica no Brasil, embora muitos confundissem essa militância com a defesa do controle de natalidade. Mas nunca estive ligada a nenhum movimento feminista, porque 
1. <http://www.nepo.unicamp.br>.

2. <http://www.cedeplar. ufmg.br/>.

3. <http://www.fflch.usp. $\mathrm{br} / \mathrm{cedhal} />$.

4. MARCÍLIO, Maria Luiza. História social da criança abandonada. São Paulo: Hucitec, 1998. era historiadora e estava preocupada com a Demografia e estudo dos arquivos do período colonial.

\section{C \& E: E a Demografia Histórica foi se difundindo?}

Maria Luiza: A Demografia não era conhecida. Tinha a ver com a Geografia, um pouco com a Sociologia, mas possuía sua própria especificidade. Depois começou a se desenvolver em alguns centros: na Unicamp, através do Nepo - Núcleo de Estudos de População ${ }^{1}$, e em Minas Gerais com o Cedeplar - Centro de Desenvolvimento e Planejamento Regional da UFMG ${ }^{2}$, onde trabalhava um importante grupo de economistas.

Assim, acho que o desenvolvimento dessa ciência foi grande, tendo presença, hoje, em várias universidades. Há vários grupos que a estudam, e diversas e importantes publicações; para isso muito contribuiu a criação do Cedhal - Centro de Estudos de Demografia Histórica da América Latina ${ }^{3}$, que criei na Faculdade de Filosofia, Ciências e Letras da USP, em 1984, e do qual fui diretora por dez anos, formando uma geração de pesquisadores entre graduados, mestres e doutores, muitos deles com bolsas de estudos. Reuni cinco departamentos para tornar o centro interdepartamental e interdisciplinar. Realizamos cursos, publicamos obras e, com isso, fomos impondo essa ciência não só na Universidade, como fora dela.

C \& E: E você manteve relações com o exterior?

Maria Luiza: Sim, recebi muitos convites ao longo desses anos e viajei bastante para participar de congressos, dar aulas como professora visitante. Tive a honra de ser convidada para dar aula como visitante na Universidade do Texas, nos Estados Unidos, depois na Califórnia, na Universidade de Berkeley, que é uma das maiores universidades americanas. Estive também na Universidade de Porto Rico, e, em Portugal, na Universidade do Minho. Tenho lá grande atividade - co-oriento teses até hoje. O mais entusiástico foi receber convite para ser diretora de estudos - eles não chamam professora - na École des Hautes Etudes en Sciences Sociales, em Paris. Agora mesmo, acaba de sair em italiano uma versão do História Social da Criança abandonada $a^{4}$ o que me deixou muito honrada. Esta pesquisa sobre a criança abandonada, realizada durante anos em Portugal e no Brasil, e que a Edusp prometeu reeditar, é um livro que trata não só de História, mas também de Sociologia, Política e até Serviço Social, Psicologia e Pedagogia. Consegui ver que criança abandonada não existia apenas na cidade de São Paulo, mas também em outras cidades - é um fenômeno mais urbano do que rural. É nas grandes cidades que o problema se torna maior. E não é só brasileiro, mas um fenômeno latino-americano; e não só deste continente, mas também europeu. Você imagina que, na Paris do século XIX - costumo chamar de o século do abandono em massa de crianças na Europa -, houve momentos em que $95 \%$ das crianças nascidas eram abandonadas? Imagine o movimento imenso que teve de ser organizado para receber e proteger essas crianças. Naturalmente que quase todas morriam. A mortalidade infantil era 
imensa nesse segmento da sociedade. Mas de qualquer maneira era preciso recebê-las e protegê-las, e foram criados vários sistemas de proteção à criança abandonada, os quais estudo em meu livro.

C \& E: Você aborda essa passagem do assistencialismo até as políticas públicas de subsídio às demandas...

Maria Luiza: É, a passagem do assistencialismo à filantropia e, depois, mais recentemente, para o Welfare State - o Estado do Bem-Estar Social -, que foi implantado na Europa, nos Estados Unidos e chegou ao Brasil, mas teve uma vida muito curta. Agora, estamos num período de globalização.

C \& E: A pesquisa com a Demografia Histórica e a sensibilidade para os problemas da criança abandonada acabaram conduzindo-a à área dos direitos humanos?

Maria Luiza: Na verdade tudo está entrelaçado, porque quando estudo não só a história da criança abandonada, mas da criança escrava, da criança ilegítima, o trabalho infantil na história, o concubinato, tudo isso são temas que convergem e com os quais nós, eu e minha equipe, sempre nos preocupamos. Há inúmeras teses orientadas por mim que enveredaram por esse caminho.

C \& E: E como são as relações com a sociedade e a política?

Maria Luiza: Há muitos convites vindos da sociedade. Um dos que muito me honrou foi para ser Assessora Científica da Secretaria que, na época, se chamava Da Criança, Família e Bem-estar Social, no governo Mário Covas, em 1996. A secretária pediu-me para escolher a área na qual desejava contribuir - a criança abandonada, as creches, a família... Resolvi aceitar um desafio - trabalhar não com a criança abandonada, mas com a criança infratora e tentar entender a Febem. Mergulhei, como sempre faço, na literatura para estudar a história da Febem, como nasceu, a que viera e quais eram os seus problemas mais importantes. Estudei a delinqüência juvenil no mundo inteiro, em livros que eu mesma importei. Enfim, percebi que havia realmente pouquíssimas pesquisas sobre a Febem, na época, e pouquíssimo conhecimento científico sobre delinqüência juvenil. Havia muitos livros de Direito, mas esse não era meu interesse. Comecei a fazer pesquisas, visitei todas as unidades, tanto de abandonados como de delinqüentes, na Capital e na Grande São Paulo, para ter uma noção. Conversei com os internos, com os juízes, com os dirigentes administrativos da Febem e descobri que havia uma desintegração total entre os vários segmentos. $\mathrm{O}$ pessoal da administração não conhecia $\mathrm{o}$ problema da Febem, os juízes pouco sabiam da sua gravíssima problemática. Desconheciam a realidade: o problema de jovens com doenças mentais graves vivendo dentro da Febem com internos normais; meninos que estavam absolutamente drogados e não podiam ficar sem a droga vivendo com outros que nunca tinham tido essa experiência; enfim, jovens com crimes gravíssimos e que precisavam de atendimento. E não existia nenhum atendimento, nem educacional, nem de qualquer outra espécie. Então comecei a escrever vários artigos sobre isso. 


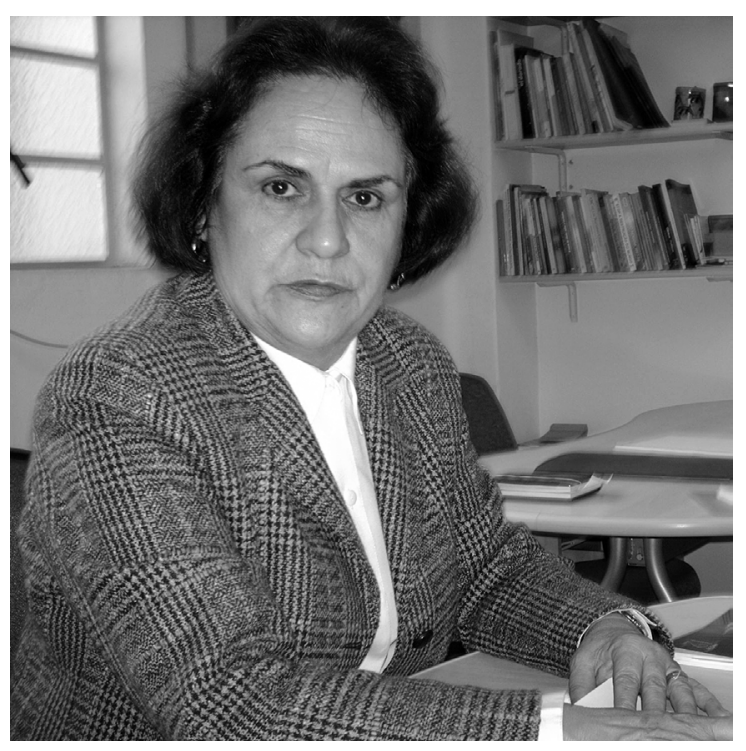

"Há pouquíssimo conhecimento sobre a delinqüência juvenil no país."
C \& E: Absolutamente nada saía do papel em termos de lei, reeducação...

Maria Luiza: É aquela história do Brasil: em todos os setores, existem a lei e a realidade, e as duas dificilmente se aproximam, porque as leis são válidas apenas para os pobres, os desvalidos, mas não valem para os ricos. Não pense que entre os ricos não haja delinqüentes - existem, e muitos. Bom, acabei pedindo demissão porque via que não seria possível fazer grande coisa, que nenhuma proposta teria condições de ir para a frente. E quero confessar:

eu abandonei de vez, embora sempre me chamem para dar entrevistas ou opinar sobre a Febem. Trata-se de um problema complexo que exige uma atenção determinada, firme, rigorosa. É preciso integração entre o Poder Judiciário, o Ministério Público e a Administração da Febem para dar uma atenção especial ao problema. A Febem gasta muito dinheiro com esses jovens, tem uma equipe de assistentes sociais e psicólogos, mas não havia advogados e médicos para eles. Os assistentes sociais e psicólogos, entretanto, que deveriam dar atenção aos meninos, ficavam o dia inteiro fechados, trancafiados mesmo - porque é tudo com grade - no setor administrativo de cada unidade. O contato com cada um dos meninos era pontual, esporádico, apenas com a finalidade de preencher os formulários que iam ser encaminhados ao juiz, dizendo se o menino tinha bom comportamento ou não, se era normal ou anormal. Enfim, davam uma opinião de algumas linhas e, de acordo com esse parecer, o juiz decidia sobre o caso e sentenciava. Dificilmente chamavam algum interno ou estabeleciam contato com o menor.

C \& E: E esses jovens vão ser arregimentados pelos comandos criminosos...

Maria Luiza: E há vários meninos lá que têm vontade de ser reintegrados, recuperados, de voltar a participar da sociedade. Muitos deles querem trabalhar ao sair. E, no entanto, depois que saem, tchau, ninguém dá mais atenção a eles, não existe um acompanhamento posterior.

C \& E: O governo não oferece nada para o jovem reabilitado?

Maria Luiza: Esse é pior ainda, porque ele vem com a pecha de ser da Febem, e com isso não arranja emprego de jeito nenhum. Aí, acaba no crime...

C \& E: Fale sobre o seu trabalho à frente da Comissão de Direitos Humanos da USP. Maria Luiza: A Comissão de Direitos Humanos foi uma das iniciativas geniais do reitor Jacques Marcovitch. Ele acabara de ser eleito, de tomar posse, quando 
reuniu aqui no Centro Acadêmico Maria Antonia um grupo de dezesseis pessoas que foram convidadas meio sem saber para quê. Dizia que era para celebrar os 50 anos da Declaração dos Direitos Humanos em 1998. Em meio a essa reunião de professores e membros da sociedade, tive a surpresa e a grande honra de ser indicada para dirigir a Comissão de Direitos Humanos. Começou aí a minha atividade junto a uma comissão provisória com o objetivo único de celebrar os 50 anos da Declaração dos Direitos Humanos na Universidade de São Paulo, no ano seguinte. Recebemos carta branca para que a comissão organizasse as atividades que julgasse necessárias, para a comemoração condigna desses 50 anos do maior documento, digo sempre, elaborado pelo homem, que é a Declaração Universal dos Direitos Humanos. Elaboramos um programa bastante denso para esse ano de 1998 - cursos, palestras, publicações - e, enfeixando tudo isso, um grande Congresso Brasileiro de Direitos Humanos, realizado na Faculdade de Direito do Largo São Francisco, onde reunimos as mais renomadas autoridades em Direitos Humanos do País. Entusiasmado, o reitor encerra o Congresso anunciando a criação do Prêmio USP de Direitos Humanos.

Eu havia proposto ao reitor que fizéssemos um Centro de Referência de Direitos Humanos, uma antiga idéia minha, sempre acalentada, que eu ainda não tinha posto em prática. Já sugerira isso na Secretaria da Justiça, quando participei do Condephe - Conselho de Defesa dos Direitos da Pessoa Humana, um órgão do governo do Estado. Várias propostas foram estudadas para a criação desse Centro de Referência, até que chegamos à idéia de fazer uma biblioteca virtual.

\section{C \& E: Como é isso?}

Maria Luiza: Uma biblioteca virtual para disponibilizar informação ao público. Eu havia tentado realizá-la tanto junto ao governo como na USP, porém sem resultado. Mas, quando o reitor me convidou para presidir a Comissão, apresentei-lhe esse projeto. Conversa daqui, reúne-se dali e comecei a desenvolver a idéia da biblioteca virtual. Não tínhamos local para guardar livros, nem dinheiro para comprá-los, nem infra-estrutura para organizá-los. Por isso, mesmo sem nenhuma experiência anterior, achei a idéia da biblioteca virtual fantástica. Entrei em contato com o professor Frederic Litto, que tinha experiência sobre o assunto, e ele me disse: "Maria Luiza, você pode contar comigo". E deu-me uma assessoria da maior competência. Assim, consegui criar a biblioteca virtual, com todo o conteúdo que imaginara. Ficou um projeto bonito e interessante.

\section{C \& E: Quantos acessos a biblioteca virtual vem registrando por dia?}

Maria Luiza: Duzentos a trezentos acessos por dia $^{5}$. Eu queria que todos os textos estivessem em português. Não precisávamos repetir o conteúdo que a ONU disponibiliza em sua biblioteca virtual sobre Direitos Humanos. Quem me ajudou a conseguir os primeiros textos no Senado e no Itamaraty, assim mesmo com muita dificuldade, foi o então deputado federal Franco Montoro, velho companheiro dos tempos da JUC - Juventude Católica. Solicitei ao Itamaraty e ao setor de relações exteriores do Senado os textos integrais que o Brasil havia assinado na ONU. Como houve dificuldade para consegui-los, organizei uma

5. <http://www. direitoshumanos.usp.br>. 
equipe de alunos/estagiários para procurá-los. Caso não existissem em português, nós traduziríamos. Esse grupo permanece conosco até hoje e são esses estagiários que se incubem de manter atualizada a biblioteca. Ela não é uma biblioteca engessada, está sempre em crescimento, enriquecendo-se de informações.

Essa Comissão de Direitos Humanos da USP é a primeira e única do Brasil. Já constitui uma entidade bastante importante no cenário nacional e tem sido chamada para várias atividades. Participamos, por exemplo, em Brasília, do Congresso Interamericano de Educação em Direitos Humanos (30 de agosto

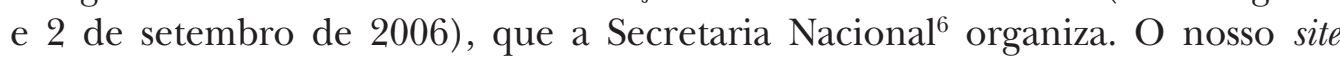
está ligado à Secretaria Nacional de Direitos Humanos. Nós somos considerados pela ONU a quinta maior biblioteca virtual de Direitos Humanos do mundo, e começamos do nada, nem verba tínhamos, nada. Há os estudantes que nos ajudam e uma secretária. Contamos também com o apoio do Centro de Informática da USP e de vários professores. Assim, vamos tocando. Sempre crescendo, com sugestões de visitantes e de professores.

C \& E: O surgimento do mestrado em Direitos Humanos é um reflexo dessas iniciativas. Você participou da criação dele?

Maria Luiza: A iniciativa não foi da Comissão de Direitos Humanos, mas incentivei muito sua criação junto à Faculdade de Direito. Tudo começou com a Fundação Ford, uma Ong norte-americana muito poderosa, sempre atenta à pesquisa e ao desenvolvimento da América Latina. Eles têm como prioridade o apoio à pesquisa e ao desenvolvimento de determinado setor previamente escolhido. Houve um momento em que elegeram a Demografia como prioridade, quando o crescimento da população no Brasil havia atingido níveis alarmantes. Eu mesma recebi apoio financeiro para desenvolver pesquisas, em nome de um melhor entendimento do problema demográfico brasileiro. Depois, a fundação Ford privilegiou a Educação. Houve então um investimento enorme em pesquisas, cursos, programas ligados ao tema. De uns três anos para cá a ênfase tem sido nos Direitos Humanos. Aqui no Brasil, diante da ausência de cursos de graduação e pós-graduação em Direitos Humanos, decidiram instituir um concurso nacional para as faculdades de Direito, já inscritas e aprovadas na Capes, que se interessassem em criar um mestrado em Direitos Humanos. Eram três prêmios para três faculdades de Direito que criassem cursos de mestrado de caráter interdisciplinar, com disciplinas oferecidas por diferentes unidades, integrando pessoas já ligadas a ações afirmativas. Aberto o concurso, tive a honra de ser convidada pela Fundação Ford para integrar a comissão organizadora do prêmio e depois para avaliar, na mesma comissão, as inscrições recebidas.

Foi então que, juntamente com o professor Guido Mântega, antigo companheiro da JUC, sempre ligado à $\mathrm{OAB}$ e aos movimentos de Direitos Humanos, iniciamos um movimento para que a Faculdade de Direito da USP apresentasse também um projeto e concorresse ao prêmio. Como membro da Comissão de Avaliação, entretanto, eu não poderia atuar de forma mais direta. Durante a

6. <http://www.planalto. gov.br/sedh>. avaliação, estivemos dois dias em São Paulo, num hotel, quase que internados, para definir as candidaturas. E, embora apenas oito faculdades tenham 
apresentado propostas, o nível era muito baixo, mesmo entre as universidades federais. A USP foi aprovada em primeiro lugar, porque apresentou o projeto de mais alto nível. Para podermos premiar outros dois projetos, sem perder a verba e a possibilidade de instauração de novos cursos, escolhemos duas outras propostas - uma da região Norte, no Pará, e outra da região Nordeste, na Paraíba - que contariam com apoio e suporte indireto da USP. Assim, foram criados três mestrados que começaram a funcionar em 2006. O prêmio foi de 570 mil reais, cada um, para cobrir os três primeiros anos de mestrado com compra de livros e equipamentos, além de financiamento de bolsas. A USP decidiu que a parte mais importante será para bolsas de alunos.

C \& E: Diante dessas dificuldades, podemos dizer que o Brasil não possui gerações preparadas ou formadas para tratar dos Direitos Humanos?

Maria Luiza: Essa é uma das questões mais sérias no Brasil - tudo é muito lento. Mas estamos nos tornando melhores. Primeiro, foi criada a Secretaria Nacional de Direitos Humanos, que é uma grande ação. Depois, ela virou Ministério e, recentemente, voltou a ser Secretaria ligada ao Ministério da Justiça. Após a Constituição de 1988, foram criados Conselhos pelo Brasil inteiro em defesa dos direitos humanos. Há comissões estaduais, em muitas Assembléias Legislativas, e tudo isso está levando a um desenvolvimento. Mas notamos que ainda é insuficiente. Há uma ignorância muito grande pelo Brasil afora. Isso foi notado na Fundação Ford, e daí essa proposta de incentivar os cursos, de formar pessoas, pois a quase-totalidade dos que atuam hoje são autodidatas. Formaram-se por ações diretas, ou leituras, ou pesquisas individuais, mas não tiveram uma formação sistemática no campo de Direitos Humanos. Há, por exemplo, preocupação em instalar uma cadeira Unesco ligada à Andi - Agência Nacional de Direitos da Infância e a outras agências. A Andi está preocupada em criar, na USP, se possível, uma disciplina optativa em qualquer dos seus institutos, diretamente ligada aos direitos humanos. Estão dispostos a dar verba para isso. Eles nos procuraram com esse intuito e, se houver realmente condição, vamos trabalhar para isso, seja na Faculdade de Filosofia, na ECA - Escola de Comunicações e Artes, seja na Faculdade de Educação, mas vamos implantar.

C \& E: O que temos hoje no Brasil parece uma colcha de retalhos, com alguns fazendo ações afirmativas, outros motivados pela determinação de cumprir a constituição...

Maria Luiza: Basta dizer que a grande maioria das pessoas ligadas às ONGs e às ações afirmativas de direitos humanos não leu a Declaração Universal de Direitos Humanos. Uma das ações que propusemos e realizamos foi a impressão de cinco mil folders com a Declaração Universal dos Direitos da Criança e cinco mil com a Declaração Universal dos Direitos Humanos. Agora, vamos publicar outro tanto em comemoração aos 10 anos da Comissão dos Direitos Humanos da USP.

C \& E: Talvez seja mesmo necessário imprimir cartilhas para divulgação.

Maria Luiza: Temos de pôr informações nas mãos das pessoas, e fazemos isso sistematicamente. Todas as conferências ou entrevistas de que participo, coloco nas 
mãos das pessoas esse documento - divulgamos o máximo possível para promover a educação em Direitos Humanos. Eu queria dizer também que essa ignorância está presente inclusive no dia-a-dia na comunicação, já que estamos falando de comunicação. Veja, estamos agora com a edição aberta de candidaturas para a sétima edição do Prêmio USP de Direitos Humanos, criado pelo antigo reitor. Todo ano, a Comissão envia convites, assinados manualmente pelos reitores da USP, a todos os reitores de todas as universidades brasileiras, para todos os grandes jornais do Brasil, para que enviem candidaturas ao Prêmio USP de Direitos Humanos. Depois, quando há a sessão solene de Comemoração dos Direitos Humanos, no dia 10 de dezembro de cada ano, no Conselho Universitário da USP, encaminhamos outra leva de convites a todas as autoridades dos mais diversos níveis, às ONGs e à grande imprensa. Nunca saiu uma única linha em nenhum jornal brasileiro de grande circulação, nenhuma notícia de que há um Prêmio USP de Direitos Humanos, nem mesmo informação sobre o convite para sessão solene.

C \& E: Nós íamos abordar esse tema: como tem sido o papel da imprensa e quais os problemas mais comuns com a comunicação?

Maria Luiza: O que se nota, talvez por falta de conhecimento, é que Direitos Humanos não é assunto interessante - não gera notícia, reportagem ou editorial. E, como as Comissões, as ONGs, as ações afirmativas têm muita exposição no momento em que há um crime hediondo, uma rebelião da Febem, ou em prisões, quando líderes religiosos têm um momento para aparecer na mídia, a população acaba concluindo que direitos humanos são sinônimo de "direitos dos bandidos", como dizem. Quando houve o primeiro e o segundo ataque do PCC aqui na cidade de São Paulo, recebemos mensagens desaforadas em nosso site, dizendo: olha aí, vocês dos Direitos Humanos, onde nós chegamos... continuem a defender esses bandidos... Isso tudo porque não temos conhecimento sobre Direitos Humanos e não recebemos apoio da mídia para ações que realizamos em diferentes frentes. A Biblioteca Virtual nunca foi noticiada, o Prêmio USP também não, só para citar como exemplo.

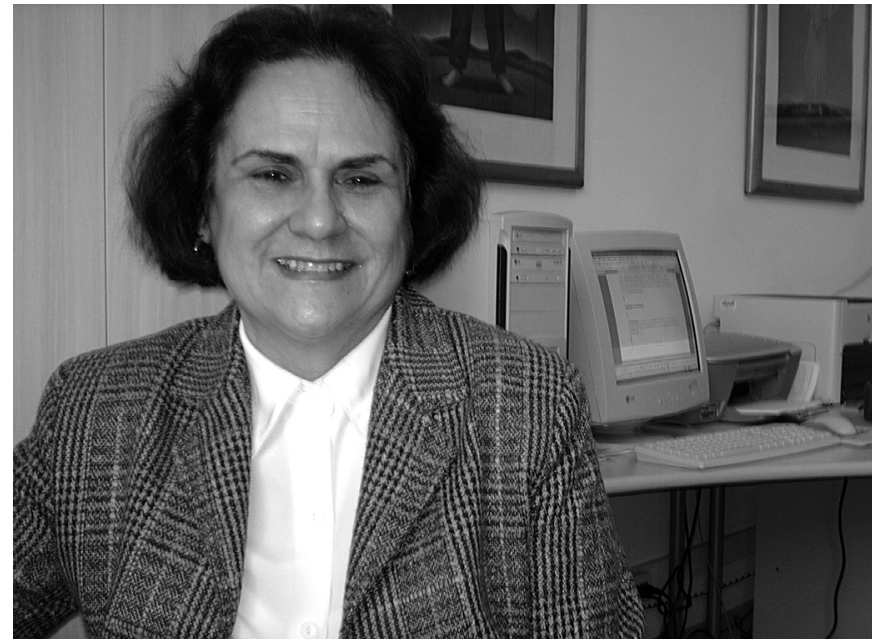

"Precisamos promover a educação em Direitos Humanos."
C \& E: A cobertura da imprensa é grande quando se trata da criminalidade...

Maria Luiza: Eu tenho falado para os meios de comunicação que a ênfase dada é para o crime. Se você abre um noticiário, principalmente os de maior audiência no Brasil, "sai sangue". Realmente, é uma notícia atrás da outra, só de crimes, como se estivéssemos vivendo apenas 
à mercê dos criminosos. E existe tanta ação absolutamente maravilhosa que se produz e reproduz na sociedade brasileira, e precisaria ser noticiada...

C \& E: E a nova tendência ao politicamente correto, age a favor dos Direitos Humanos? Maria Luiza: É uma coisa muito cômoda, na verdade. O que caracteriza a cultura brasileira, em geral, é a crença confortável de que os problemas se resolvem com mudanças na lei, na norma, na forma. Toda vez que temos um problema grave, agudo, em vez de estudá-lo, de analisar suas causas ou sua história, partimos para propostas de mudança na lei, ou no nome que ela tem. Por outro lado, a palavra menor foi proscrita do vocabulário, e com razão, porque era tida como um estigma. O menor era o filho do pobre, do negro, do favelado, e a criança era da classe dominante, da classe média. Então, de fato, o Estatuto da Criança e do Adolescente (ECA) veio equalizar a criança e os direitos de toda criança, como previa a Declaração Universal dos Direitos da Criança, sem discriminação de cor, raça, religião, origem, riqueza ou posição social. Essa criança precisa ter seus direitos garantidos e a Constituição de 1988 fez isso, assim como o ECA o confirmou. O problema é que, na realidade, sempre estamos muito preocupados com a nomenclatura e menos com a realidade. Ainda hoje eu ouvia na rádio alguém dizer, em uma propaganda eleitoral, que, se eleito governador, iria acabar com a Febem. Bom, acabar com o nome Febem? Ela já teve vários nomes. Já foi SAM - Serviço de Atendimento ao Menor, já foi Funabem... Agora, mais uma vez, propõe-se a mudança do nome, porque estigmatizou o jovem que por ela passou. Tudo bem, mas não é o nome que vai mudar a realidade... Essa tentativa de resolver tudo por meio de decretos tem tornado piores os problemas sociais no Brasil.

C \& E: Nós temos assistido à polêmica sobre a adoção de cotas...

Maria Luiza: É a mesma coisa. Não se estuda, não se analisa o problema grave que será gerado e que emergirá com essa distinção entre brancos e afro-descendentes. Há preconceito, há discriminação, mas isso se resolve com Educação. Mas ela é muito lenta, e as pessoas querem ver resultados na hora; por isso, baixam-se os decretos pensando que a coisa está resolvida. Mas não está! Ao contrário, vai agravar os problemas de racismo que existem desde o começo do século XIX, quando se discutia a superioridade racial dos brancos. Essas posições vão ser retomadas de forma diferente. É a tendência em resolver os problemas por meio de normas. Baixa-se decreto e está tudo resolvido. Não se estudam as causas e as conseqüências, não se realizam pesquisas sérias para, a partir delas, fazer um diagnóstico. Estamos conseguindo alguns progressos importantíssimos, mas ainda não são suficientes.

C \& E: Falando de educação em Direitos Humanos, os professores estão preparados para tratar disso?

Maria Luiza: Não, não estão. Para auxiliá-los nesse sentido, resolvemos publicar um CD-Rom com a Declaração dos Direitos do Homem e do Cidadão para ser distribuído pelas escolas. Mas não queríamos apenas distribuí-los, queríamos pre- 
comunicação \& educação • Ano XII • Número 1 • jan/abr 2007

parar os professores, não só os da área de humanas, mas também os de química ou matemática, para que todos fizessem uso desse conteúdo. Para distribuir os CDs, entramos em contato com as secretarias de educação do Município e do Estado a fim de organizarmos encontros na USP com representantes de todas as escolas. Nesse encontro, o professor Enrique Ricardo Lewandowski, membro da Comissão de Direitos Humanos e, hoje, Ministro do Supremo Tribunal Federal, o professor Fábio Brito, diretor do Colégio de Aplicação, e eu falamos para os professores sobre Direitos Humanos de um ponto de vista histórico, jurídico e pedagógico - sobre como aplicá-lo em sala de aula. Usamos um data show para exemplificar o uso do CD em atividades didáticas. Com a Secretaria Municipal da Educação foi um sucesso - reunimos cerca de $90 \%$ das escolas municipais nessas conferências. Mas com a Secretaria Estadual foi um desastre, e o encontro não aconteceu. O secretário convidou-me então para uma sessão em uma escola da periferia de São Paulo, à qual só compareceu meia dúzia de alunos. Para corrigir os erros, fui convidada a proferir uma videoconferência para os colégios da zona leste. Foi interessante, três horas de conferência a distância, com discussão direta, mas que não atingiu a todos. Também não sei como foi feita a distribuição dos CDs entre as escolas estaduais do Ensino Médio.

\section{C \& E: Quais são os próximos passos da Comissão?}

Maria Luiza: Há duas grandes comemorações: em 2007, a Comissão de Direitos Humanos da USP completa dez anos. Estamos reunindo os novos membros, recém-nomeados pela atual reitora, para elaborar um programa de atividades para essa data. Em 2008, comemoram-se 60 anos da Declaração Universal dos Direitos Humanos, para a qual a Comissão também deve fazer uma celebração à altura deste documento. Concluo dizendo que nosso principal objetivo é convidar nossos cidadãos a ler a Declaração Universal dos Direitos Humanos, que está com todo o destaque em nosso CD e site. Temos muito interesse em enviar folders para as escolas que queiram esse documento em mãos. É o maior documento, repito, elaborado pelo homem - através de uma comissão de grandes filósofos que se reuniu por iniciativa da ONU, logo depois da Segunda Guerra -, a fim de sintetizar em 30 itens os direitos não apenas individuais e políticos, mas também os econômicos, sociais, culturas e ambientais que interessam a toda a humanidade. Acho que nós, brasileiros, temos, e é minha luta, sempre de fazer chegar esse documento a todos os cidadãos. É uma cultura básica... E todos os seus itens estão presentes na Constituição brasileira.

C \& E: Como foi a experiência de produzir e ancorar um programa para a Televisão na Rede Vida?

Maria Luiza: Apesar de ter sido por pouco tempo, uns seis programas, foi uma experiência muito interessante e nova para mim. Eu dirigi um programa chamado Caminhos para os Direitos Humanos, com uma hora de entrevistas com pessoas que eu mesma selecionava e convidava para participar. Mas a Rede Vida luta com grandes dificuldades financeiras e o programa não pôde continuar. Isso foi antes de eu ser presidente da Comissão de Direitos Humanos da USP. 


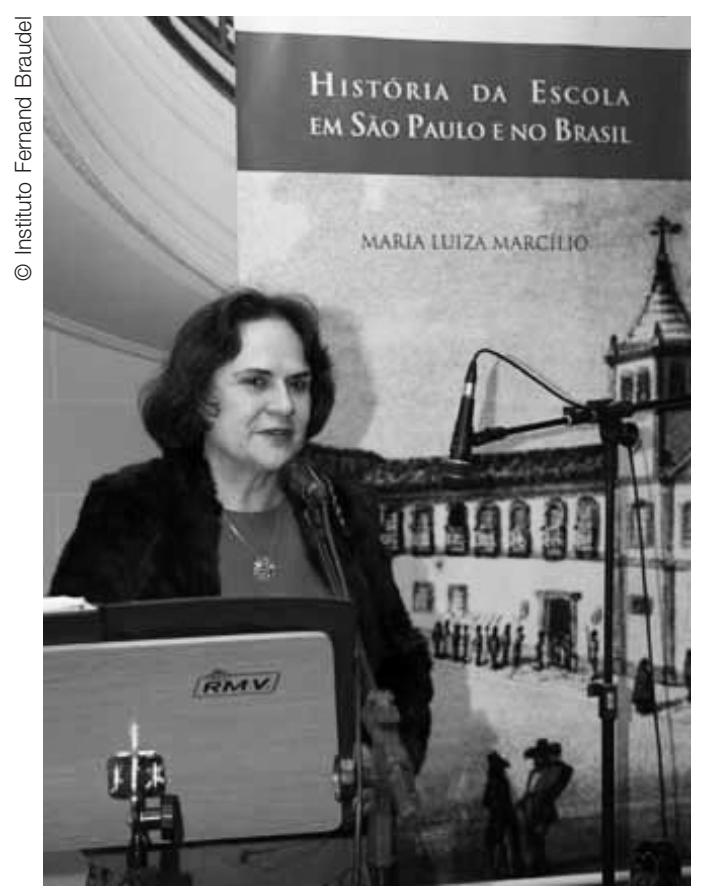

"A educação em Direitos Humanos requer professores preparados."
C \& E: O que a levou a escrever o livro História da escola em São Paulo e no Brasil ${ }^{7}$ ?

Maria Luiza: Esse livro surgiu de um projeto meu, anterior à criação da Cedhal, em 1984, voltado à história da criança no Brasil. Depois, com a experiência com os jovens da Febem - na concepção da ONU, a infância vai até os 18 anos -, fui convidada, em 2000, pelo Instituto Fernand Braudel ${ }^{8}$, para fazer uma história da escola, parte de um estudo intitulado História da Educação na cidade de São Paulo. Este pequeno instituto, ligado à FAAP e dirigido por um grupo de eminentes brasileiros - economistas, empresários, políticos -, dedica-se à pesquisa séria, de vários segmentos e setores da sociedade. Apesar de achar a proposta um grande desafio, como havia começado minha carreira como professora primária - na capa do livro, estou com os aluninhos de segundo ano, na periferia - e depois como professora do então chamado "ginásio oficial”, também na periferia, fiquei estimulada. Sempre digo aos alunos que a pesquisa deve ser guiada por nosso interesse e nossa paixão, senão não sai nada que preste. Eu sempre fui apaixonada pela escola, principalmente pela pública, onde trabalhei. A proposta do Instituto Fernand Braudel foi então uma possibilidade de fazer alguma coisa nova, utilizando toda a imensa documentação que havia reunido e toda a experiência com o povo, com a Demografia histórica dos mais humildes, com os quais sempre trabalhei. Nesses quatros anos em que estive no Instituto Fernand Braudel, com total apoio deles, mergulhei no trabalho para elaborar essa história da escola. Consegui mostrar que temos vivido sempre, e até hoje, numa situação de atraso em relação à educação, mesmo se considerarmos países semelhantes ao nosso, aqui da América Latina, como a Argentina, o Uruguai o Chile, a Costa Rica e Cuba, que tiveram uma experiência educacional precoce, muito mais ampla e abrangente que a nossa. Além disso, esses países criam universidades desde o século XVI.

Fui somando todas essas experiências e descobrindo com as pesquisas empíricas - ao analisar a documentação dos arquivos - que havia uma realidade que a história da educação não se dava conta, pois não se tinha constituído a partir de uma realidade concreta. Voltei aos arquivos para desvendar a realidade educacional das primeiras letras às primeiras aulas do secundário, até chegar à situação de hoje. Com toda a experiência de demógrafa que sabe lidar muito bem com números, com estatísticas, com os institutos de pesquisa e suas cifras. Pude, numa fase mais madura de minha vida de pesquisadora, ter uma visão crítica da realidade educacional brasileira. Em minhas viagens internacionais
7. MARCÍLIO, Maria Luiza. História da escola em São Paulo e no Brasil. São Paulo: Instituto Fernand Braudel /Imprensa Oficial, 2005. 485 p.

8. <http://www.braudel. org.br>. 
sempre procurei me relacionar, entrevistar e conversar com pessoas ligadas à história da educação, à história social da criança, para dar aos meus estudos maior amplitude. Esse livro, publicado em julho de 2005, já está quase esgotado, e foi um dos dez finalistas do Prêmio Jabuti de 2006. Não ganhou o prêmio, mas já é uma honra ter sido indicada.

Dividi em três partes a história da escola, que é a do Brasil também. O período das origens, que vai até 1870; depois, a implantação do sistema público com Pombal e o desenvolvimento no Império, que foi terrível; e o período que denomino século da história, que vai de 1870 a 1990, quando se implantam modelos escolares no Brasil, os quais não havia antes. Depois, da década de 1990 para cá, é outra realidade: a pressão dos organismos internacionais sobre países que possuíam uma grande, enorme, taxa de analfabetismo. O Brasil era um dos dez maiores países do mundo em número de analfabetos, com taxas muito vergonhosas, se comparadas internacionalmente; com o maior índice de reprovação escolar e com altíssimo índice de evasão escolar. Enfim, tínhamos muitos problemas graves. O governo Fernando Henrique deu importância à escola de base, para onde foi direcionada a maior parte das verbas. Com esse esforço, pela primeira vez, e muito atrasados em relação a outros países, chegamos a escolarizar $97 \%$ das crianças em idade escolar. Isso tem reflexos poderosos no desenvolvimento do Brasil. Sem escola de base não há desenvolvimento, não há o combate às desigualdades sociais. $\mathrm{O}$ Brasil é outro campeão, infelizmente, nesse quesito também. E só conseguirá reverter esse quadro com efetivas políticas de médio e longo prazo. Uma delas é a escola fundamental de qualidade para todos.

Resumo: Maria Luiza Marcílio ocupa o importante cargo de presidente da Comissão de Direitos Humanos da Universidade de São Paulo, onde criou a primeira biblioteca virtual em língua portuguesa sobre direitos humanos. Diplomada em História pela Universidade de São Paulo - USP e doutorada pela École des Hautes Études en Sciences Sociales, sua tese sobre a cidade de São Paulo foi marco da pesquisa em demografia histórica na América Latina. Publicou importantes obras sobre o abandono da criança e a questão da educação. Nesta entrevista, ela defende a Declaração Universal dos Direitos Humanos como o mais importante documento elaborado pelo homem. Afirma que o Brasil só poderá combater a desigualdade social com uma escola de base de qualidade para todos, além de defender a pesquisa como ferramenta essencial para a tomada de decisões, em qualquer área do saber e da sociedade.

Palavras-chave: direitos humanos, biblioteca virtual, educação, pesquisa demográfica histórica, desigualdade social.
Abstract: Maria Luiza Marcílio has the important function of president to the University of São Paulo Human Rights Commission, in the name of which she created the first Human Rights virtual library in Portuguese language. Bachelor in History by University of São Paulo - USP and Ph.D. by École des Hautes Études en Sciences Sociales, her thesis on São Paulo city was as milestone in historical demography research in Latin America. She published important works on child abandonment and on the issue of education. In this interview, she defends the Universal Declaration of Human Rights as the most important document ever written. She affirms that the only way for Brazil to fight against social inequality is offering quality basic education to all, besides defending research as an important tool to decision taking, in any area of knowledge and society.

Keywords: human rights, virtual library, education, historical demographic research, social inequality. 